\title{
Fabricated or induced illness in the oral cavity in children. A systematic review and personal experience
}

\author{
DOROTA OLCZAK-KOWALCZYK ${ }^{1}$, BEATA WOLSKA-KUSNIERZ ${ }^{2}$,EWA BERNATOWSKA ${ }^{2}$ \\ ${ }^{1}$ Department of Paediatric Dentistry, Warsaw Medical University, Warsaw, Poland \\ ${ }^{2}$ Department of Immunology, The Children's Memorial Health Institute, Warsaw, Poland
}

\begin{abstract}
Introduction: Münchausen syndrome by proxy (MSBP) describes a pattern in which a caregiver induces a disease in a child. The symptoms may manifest in the oral cavity.

Material and methods: PubMed was researched for articles between 1990-2014, presenting manifestations of MSPB, following PRISMA 2009 guidelines, and an in-house case of MSBP with oral manifestations was presented.

Review: Among 66 articles presenting MSBP symptoms, four included descriptions of oral lesions in five children. They included: tooth loss, ulcerations and ulcers on oral mucosa, scars due to old, healed lesions, bleeding, black tongue, polysialia, and discolouration and swelling in the lips. Münchausen syndrome by proxy with participation of the mother was diagnosed in four cases.

Case: A 13-year-old girl was hospitalised because of a non-healing ulcer of the septum, loose and lost mandibular teeth, skin lesions, and suspected immunodeficiency. She had been hospitalised numerous times at other facilities. Consultations and diagnostic tests did not confirm an organic disease. The patient and her mother agreed to undergo all examinations, and some symptoms 'went away' during the examinations. The behaviour of the patient and her mother during hospital stays, ambulatory care, and the psychiatric observations all pointed towards MPSB. They refused further treatment at the present facility.

Conclusions: A dentist should take into account the potential 'fabrication' of symptoms in a child by the latter or by a caregiver. Consultations with a paediatrician or psychiatrist enable a diagnosis and treatment.
\end{abstract}

Key words: Münchausen syndrome by proxy, factitious disorder, oral cavity, tooth loss, immunodeficiency.

(Centr Eur J Immunol 2015; 40 (1): 109-114)

\section{Introduction}

The battered child syndrome is a broad term including physical, psychological, and sexual abuse, as well as negligence [1]. Münchausen syndrome by proxy (MSBP), currently also called fabricated or induced illness in children or factitious disorder by proxy (FD by proxy), is a particular example of that [2-5]. It was described for the first time in 1977 by Roy Meadow. In the described case, the mother of a 6-year-old boy manufactured proof of an organic disease in her son by adding her own blood to his urine. She then exposed her son to numerous diagnostic tests, including some under general anaesthesia [6].

The disorder consists of the invention of disease symptoms in a child by his/her caregiver, fabricating proof of disease, or inducing a disease in a child that may even lead to their death. Most often, in $85 \%$ of cases, the disease is initiated by the mother of the child, and less often by the father or other caregivers [2, 3, 5, 7-12]. According to the American classification of mental disorders Diagnostic and Statistical Manual of Mental Disorders (DSM-IV), the aim of the perpetrator is to become a sick person by means of a proxy, i.e. the child [13].

DSM-IV diagnostic criteria include:

intentional fabricating or replicating somatic or psychological symptoms in other people who are directly cared for by the perpetrator,

the aim of such behaviour is to cause the symptoms of the disease in that person (the proxy),

Correspondence: Dorota Olczak-Kowalczyk, Department of Paediatric Dentistry, Warsaw Medical University, Miodowa 18, 00-246 Warsaw, Poland, e-mail: do-k@o2.pl 
there are no external motives (such as pecuniary benefits),

the aforementioned behaviour cannot be qualified as other mental disorders [3, 11, 13, 14].

Münchausen syndrome by proxy is not easy to diagnose since the criteria are not specific [2-4, 7, 8, 11, 12, 14]. Furthermore, the problem is presented most often in small children up to two years old and seldom older than six. What makes the diagnosis even more difficult in the case of older children is their cooperation with the caregiver, since the child craves the caregiver's approval. Older children and adolescents may take an active part in fabricating the disease, and, should the caregiver be absent, may induce the symptoms themselves $[15,16]$. This required differentiating MSBP from Münchausen's syndrome (chronic FD) [3]. Libow et al. described as much as 42 cases, and Peebles et al. described 6 cases of children fabricating their diseases [5, 17].

Apnoea, seizures, bleeding, central nervous system depression, gastrointestinal dysfunction (vomiting, diarrhoea, and obstruction), fever, skin rashes, cough, poor weight gain, foot ulcers, and perianal lesions may all be clinical symptoms of MBPS. Bleeding from the ears or nose, tooth loss, nasal excoriation, otorrhea, chronic external otitis, and oral lesions are symptoms manifesting within the head region $[2,3,5-8,10,11,18]$.

In Poland three forms of MSBP are differentiated: mild, when the physician is presented with invented symptoms in the child,

moderate, when the induced symptoms are relatively mild and are not life threatening,

severe, when the induced symptoms may be life threatening [19].

However, it was also suggested by some medical professionals that the syndrome itself does not exist, and is itself a 'fabrication' [20]. That seems harmful, since it is in the child's best interest that one should take into account any direct or indirect participation of caregivers in fabricating diseases, especially the potential intergenerational transmission of abnormal illness behaviour from the caregiver to the child [4]. According to Trejo-Hernández et al., 5 out of 14 mothers who induce symptoms in their children suffered from MSP themselves as children [9]. In the Bass study, in a group of 28 mothers with a putative diagnosis of fabricated or induced illness in children, in $2 / 3$ a chronic somatoform disorder or factitious disorder (or both) were detected, and $54 \%$ of them were severely abused as children [21].

Münchausen syndrome by proxy diagnosis requires the participation of many physicians, with different areas of expertise $[2-4,7,10,14,21]$. Since the symptoms induced in children by third parties may manifest in the oral cavity, it is also important for dentists to participate in the medical diagnosis.
The study is to present oral lesions symptomatic of MSBP based on publications and personal experience. It also attempts to present the difficulties encountered in diagnosing MSBP, based on personal experience.

\section{Material and methods}

Following PRISMA 2009 guidelines, PubMed was researched for articles published between 1990-2014, featuring oral manifestations of MSBP. The researched terms included: 'Münchausen syndrome by proxy' and 'factitious disorder by proxy', also together with 'oral cavity', 'oral mucosa', 'lip', 'tongue', 'submandibular gland', 'parotid gland', 'palate', 'tooth', 'stomatitis', 'oral ulcers', 'glossitis', 'gingivitis', 'periodontitis', 'caries', 'abscess, 'tooth loss', 'oral pain', and 'bleeding'. Based on abstracts, papers on MSBP with no oral manifestations were excluded. Only articles presenting a high probability of MSBP with oral lesions or its diagnosis were fully analysed.

The presentation of the in-house case included medical history and the results of medical file analysis, of the clinical examinations (paediatric, immunological, laryngological, dental, histological, and psychiatric), and of additional examinations.

\section{Publication review}

Among 574 articles on MSBP researched on PubMed, 66 abstracts were analysed. Only four, presenting children aged from nine months to seven years, were qualified for full analysis. Münchausen syndrome by proxy clinical symptoms and causes are presented in Table 1.

Tamay et al. presented oral lesions in two siblings (a two-year-old girl and a six-year-old boy) resulting from the oral administration of a household-cleaning product containing sodium hydroxide by their mother. It led to the death of the two-year-old girl, who was first abused [22]. In the case described by Clin et al. the mother was fabricating her nine-month-old baby's disease in the same way, but the baby survived owing to a fast diagnosis [23].

In all reported cases the diagnosis of MSBP was difficult. The two-year-old girl, who died, was hospitalised twice. The reason of her first hospitalisation was a suspicion of Stevens-Johnson syndrome. During the second hospitalisation cicatricial pemphigoid was suspected.

Porter et al. reported tooth loss in a 2.5-year-old boy [24]. In this case Histiocitosis X and Type IV Ehlers-Danlos syndrome were initially considered.

Sridharan et al. described children hospitalised for 'spontaneous' bleedings [15]. The reason for that was revealed with the example of a seven-year-old girl. The child was biting on the oral mucosa, spitting the blood out, and spreading it on her forehead. What is interesting is that the other children ( 3 girls and 1 boy) reported to the hospital two days later with similar symptoms. They all belonged 
Table 1. Clinical symptoms of Münchausen syndrome by proxy and their causes in publications

\begin{tabular}{|c|c|c|c|c|c|c|}
\hline Source & Sex & Age & $\begin{array}{l}\text { Diagnosis } \\
\text { / person } \\
\text { causing } \\
\text { behaviour }\end{array}$ & Oral cavity manifestations & Other, main clinical symptoms & Cause \\
\hline \multirow[t]{2}{*}{$\begin{array}{l}\text { Tamay } \\
\text { et al. [22] }\end{array}$} & $\mathrm{F}$ & $2 \mathrm{yrs}$ & $\begin{array}{l}\mathrm{MSBP} / \\
\text { mother }\end{array}$ & $\begin{array}{l}\text { episode 1: gingivitis and } \\
\text { erosions, bleeding } \\
\text { episode 2: perioral lesions and } \\
\text { mucosal } \\
\text { bleeding, superficial ulcers on } \\
\text { the tongue, cicatrisation on the } \\
\text { lower lip }\end{array}$ & $\begin{array}{c}\text { episode 1: right eyelids due to } \\
\text { scarring, purulent discharge and } \\
\text { cicatrisation under the right eyelid, } \\
\text { mild stridor, flushing, small black } \\
\text { discolouration on the frontal surface } \\
\text { of the chin } \\
\text { episode } 2 \text { : fever, vomiting, } \\
\text { symblepharon on the right eye, } \\
\text { inspiratory stridor and dyspnoeic } \\
\text { attacks, death following massive } \\
\text { bleeding from mouth }\end{array}$ & $\begin{array}{l}\text { household-cleaning } \\
\text { product containing } \\
\text { sodium hydroxide }\end{array}$ \\
\hline & M & $6 \mathrm{yrs}$ & $\begin{array}{l}\mathrm{MSBP} / \\
\text { mother }\end{array}$ & $\begin{array}{l}\text { purplish discolouration and } \\
\text { swelling in the lips, aphthous } \\
\text { ulcers, scars due to old healed } \\
\text { lesions on the lips and tongue, } \\
\text { sudden episode of oedema in } \\
\text { the lips, mucosal bleeding foci } \\
\text { in gingivae }\end{array}$ & $\begin{array}{c}\text { generalised maculopapular rash after } \\
\text { heating his routine breakfast }\end{array}$ & \\
\hline $\begin{array}{l}\text { Clin } \\
\text { et al. [23] }\end{array}$ & $\mathrm{F}$ & $\begin{array}{c}9 \\
\text { mths }\end{array}$ & $\begin{array}{l}\text { MSBP / } \\
\text { mother }\end{array}$ & $\begin{array}{l}\text { inflammatory lesions, oedema } \\
\text { of interior lip palate and tongue, } \\
\text { black tongue with aspect of } \\
\text { mucitis and early desquamation, } \\
\text { drooling and salivation with } \\
\text { dysphagia }\end{array}$ & $\begin{array}{c}\text { inflammatory pharyngeal lesions, } \\
\text { vomiting, esophagitis, fever, caustic } \\
\text { esophagitis }\end{array}$ & $\begin{array}{l}\text { acid-based powder } \\
\text { in child food and on } \\
\text { cuddly toys/mother }\end{array}$ \\
\hline $\begin{array}{l}\text { Porter } \\
\text { et al. [24] }\end{array}$ & M & $\begin{array}{l}2.5 \\
\text { yrs }\end{array}$ & MSBP & $\begin{array}{l}\text { tooth loss, bloody oral } \\
\text { secretions }\end{array}$ & $\begin{array}{l}\text { diarrhea, cough, retching, } \\
\text { esophageal perforation, hematenesis, } \\
\text { retrograde intussusceptions, } \\
\text { bradycardia }\end{array}$ & $\begin{array}{l}\text { unknown (speculation: } \\
\text { bradycardia - carotic } \\
\text { artery stimulation, } \\
\text { oesophageal perforation- } \\
\text { trauma for some foreign. } \\
\text { object, retrograde } \\
\text { intussusceptions- } \\
\text { a foreign body inserted } \\
\text { into the rectum) }\end{array}$ \\
\hline $\begin{array}{l}\text { Sridharan } \\
\text { et al. [15] }\end{array}$ & $\mathrm{F}$ & $7 \mathrm{yrs}$ & $\begin{array}{l}\text { MSBP / MS } \\
\text { / mother } \\
\text { taking part } \\
\text { or aware } \\
\text { of child } \\
\text { behaviour }\end{array}$ & $\begin{array}{l}\text { multiple small ulcerations on } \\
\text { buccal mucosa }\end{array}$ & $\begin{array}{l}\text { facial bleedings - forehead, cheek, } \\
\text { and scalp }\end{array}$ & $\begin{array}{l}\text { biting on oral mucosa } \\
\text { and applying blood to } \\
\text { the forehead }\end{array}$ \\
\hline
\end{tabular}

to different age groups (from 3 to 10 years), and were from different families, but came from the same town. The study confirmed MS, but hinted at MSBP since the children bled also from places other than the face, and some of them were too young to have been able to cause such symptoms themselves (three children were only three years old).

\section{Case study}

A 13-year-old girl with a non-healing ulcer of the septum, loose teeth, and four lost incisors and mandibu- lar canine was admitted to the Immunology Unit of the Children's Memorial Health Institute with a suspicion of immunodeficiency.

When questioned, her mother described the following symptoms that had persisted for about two years: itchy nose and throat, progressive septum deformity, itchy skin, eating difficulties and regurgitation through the nose, long and chronic mild fever, loose stools, and hair loss. The mother also claimed 'spontaneous' loss of a healthy looking pinkie nail. For the above-mentioned reasons, she was hospitalised many times at various facilities. According 
to the medical files presented by the mother, no organic disease was diagnosed; however, a psychological disorder was suspected. The patient's mother also presented her conclusions and observations on her daughter's disease.

The physical examination of the girl upon hospital admission revealed a low body mass, nose deformity, a mucus discharge in the nose, dried skin with many visible scratches, eczema on the skin of hands and feet, habitual nose pinching, and inserting the whole pinkie into the nose. The lymph nodes were not enlarged at physical examination. The observation during the hospital stay did not reveal any abnormal stool or mild fever. The examination results did not present any inflammations, haematological diseases, or immune system disorders (normal immunoglobulin levels, lymphocyte count, function tests, and NBT).

Many consultations and diagnostic tests were carried out during hospitalisation. The girl and her mother eagerly agreed to all diagnostic tests, including invasive procedures.

The laryngological examination revealed no oral, nasopharyngeal, or aural lesions. Tongue function was described as normal. However, the patient appeared to be able to control the mobility of her soft palate, which made it possible to regurgitate food through her nose. The nose appeared to be deformed with decreased permeability, septal lesion, and allergic catarrhal inflammation. The CT scan of paranasal sinuses presented a deformity of the cartilage of the septum with no bone lesion, polyp-like calluses on the alveolar recess of the right maxillary sinus, and a thickening of the mucous membrane of the nasal concha. Since the patient had difficulties with lying down, despite being only 12 years old, the CT scan was performed under general anaesthesia. Anti-allergic treatment was prescribed. The girl was initially qualified for a surgical septum correction.

Although no symptoms were detected at the ear examination, a hearing assessment was performed, because the mother insisted the child was hearing impaired, and the results were normal.

An intraoral dental examination detected a lip collapse and a shortened jaw. The skin on the face and around the mouth and the lips did not present any lesions. The submandibular and neck lymph nodes were intangible at physical examination. There was no pain, cracks, asymmetry, or movement limitation within the temporomandibular joints. Intra-orally, incisors and a mandibular canine were missing, the alveolar crest bone was not healing properly, and necrotic bone tissue was secreted; no pain was felt at palpation, and no acute inflammation symptoms were detected in that area. The oral mucosa was smooth, pink, and moist without any lesions. Increased mobility of mandibular premolars $(34,35,44$, and 45) and upper medial incisors (11 and 21) was detected. No gingivitis or periodontitis was detected despite poor oral hygiene. According to the mother, the lower teeth 'fell out' within one hour without causing pain or bleeding. The girl did not answer any questions. The pantomograph revealed osteolytic changes within the frontal part of the mandible (from 34 to 44) and expansion of the gingival crevice around the gap (Fig. 1).

The radiographic image did not reveal any mandibular incisor abnormalities. The mother and the daughter were informed that a consultation with a dental surgeon was necessary. While awaiting the consultation, the dental check-up performed three days later did not reveal any increased mobility of tooth 11 and 21 . The dental surgeon confirmed the dental assessment, and the histopathological report did not feature any mandibular lesions in the areas where teeth were lost.

Based on the consultation and examination results it was not possible to determine organic causes of the symptoms observed in the patients. Suspecting psychosomatic causes, the girl was sent for a psychiatric consultation. From the moment that the examination results confirming

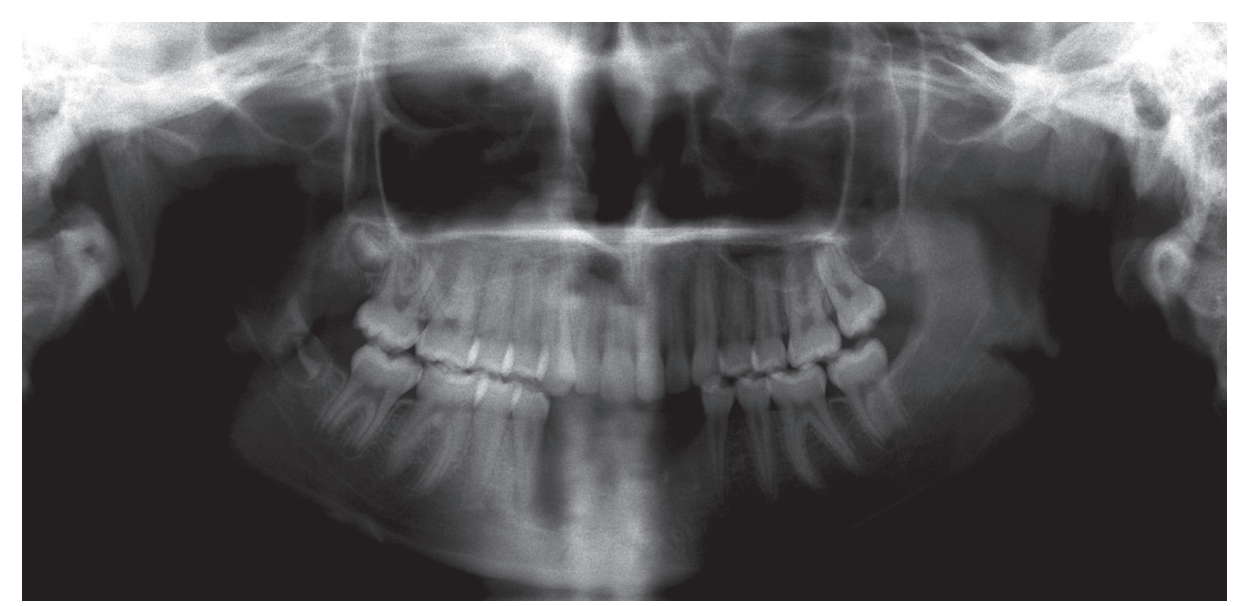

Fig. 1. No incisors and mandibular canine, expansion of the gingival crevice around the gap, osteolytic changes within the frontal part of the mandible 
the disease was not organic were discussed and the psychosomatic disorders were pointed out, cooperation with the patient and her mother deteriorated.

At the psychiatric evaluation the girl presented a good auto- and allopsychic orientation, was relational, presented a stable mood, and answered questions in a logical and coherent way, with no speech or flow impairment, and with no productive symptoms. The psychiatrist was preoccupied by her light approach to her somatic symptoms, which were impairing her functioning.

The girl and her mother were not happy with the psychiatric consultation. After being discharged from hospital, the mother presented herself at the Immunology Clinic; however, she refused a previously planned hospitalisation that was meant to sum up all the examination results. The observation of the behaviour of the patient and her mother during hospital stays and ambulatory care, the reactions during phone calls, and the conclusions of the psychiatric consultant all pinpointed Münchausen syndrome by proxy (moderate form). Both the mother and the child were advised to carry on with the psychiatric supervision, and their GP and local social services were informed about that fact. It was later confirmed by phone that the treatment was continued, and four years later that the girl was doing well.

\section{Discussion}

The diagnosis of factitious disorders is a complicated process requiring the cooperation of many different specialists. It requires a thorough diagnosis to exclude organic clinical symptoms, and the observation of both the caregiver and the patient for psychosomatic disorders. In the present case, the loss of permanent teeth, without prodromes (pain, inflammation, and granulating lesions), no inflammation of periodontal tissues in the vicinity of other teeth and on oral mucosa, and good immune responses in laboratory tests excluded periodontitis as a symptom of systemic disease. The clinical picture, histopathology reports, and lab tests also excluded hyperplasia (including histocytosis) and hypophosphatasia. The occurrence of new symptoms, such as another group of loose teeth without any other clinical symptom, while awaiting the results of the examinations hinted at self-mutilation by the child or mutilation by the mother. This theory was confirmed by the disappearance of the symptoms when the medical efforts were intensified, i.e. the examination results were discussed with the mother, and especially when she was informed about the difficulties in result interpretation and the need for additional examinations. The mother was willing to 'help' and agreed to all recommended diagnostic procedures, apart from the psychiatric evaluation.

It is characteristic of parents inducing diseases in their children to agree to even the most invasive diagnostic procedures [25]. In the Trejo-Hernández et al. study they were performed in as many as $77 \%$ of the children [9].
The analysis of the mother's and patient's behaviour presented the main symptoms of MSBP, i.e. the existence of diseases that are factitious or induced by the mother, the request of further diagnostic tests, the mother's declarations on the disease causes, and emphasis put on the inefficacity of diagnostic facilities [26].

However, it is hard to determine which of the observed symptoms result from the mother's actions and which resulted from the actions of the child $[15,16]$. Publications also suggest oral manifestation, also within the oral cavity, may be self-induced [15, 27-32].

In the Sridharan et al. study, a girl hospitalised for 'spontaneous' bleedings in the head region was biting on the oral mucosa of her cheeks and tongue, which caused bleeding, and then spiting the blood and spreading it on her forehead. She said she behaved that way to get others' attention. The study suggested that the mother could have helped in the induction of symptoms or could have been aware of her child's behaviour. The study also emphasised the negative reaction of parents to suggestions about getting psychiatric evaluations and the displayed discontentment and anger, even when answering the psychiatrist's easiest questions, which also occurred in the case of the patient's mother [15]. The Bas C and Jones D studies revealed frequent occurrence of chronic somatoform disorders or factitious disorders (or both) in mothers with a putative diagnosis of fabricated or induced illness [21].

In the presented study, the 'disease' started when the girl was about 11 years old, and as studies in adults indicate, FD can start at puberty [33]. Özmen et al. described the case of an 11-year-old girl with a three-month history of clear discharge from her right ear [34]. The patient was proven to be putting water with saliva into her right ear canal. Contrary to Sridharan et al. and the present case, the quoted authors did not prove any participation of relatives (be it awareness or active participation) in falsifying disease symptoms [15]. On the other hand, MSBP is not only observed in small children. It was also reported in teenagers and even adults $[35,36]$.

\section{Summary}

The diagnosis of these factitious disorders, both Münchausen syndrome and Münchausen syndrome by proxy, requires the cooperation of different specialists. A dentist should also take into account the potential 'fabrication' of symptoms in a child, by the latter or by a third party, since MSBP may present symptoms involving the oral cavity. Consultations between dentists and paediatricians or psychiatrists enable a diagnosis and thereby start the necessary psychiatric and psychological treatment. It is crucial to remember that Münchausen's syndrome by proxy may even cause the child's death $(9-10 \%)$. Therefore early diagnosis of symptoms induced by the child him/herself is important, as it may result in the development of a chronic pattern of illness falsification. 
The authors declare no conflict of interest.

\section{References}

1. Kellogg N; American Academy of Pediatrics Committee on Child Abuse and Neglect (2005): Oral and dental aspects of child abuse and neglect. Pediatrics 116: 1565-1568.

2. Flaherty EG, Macmillan HL; Committee On Child Abuse And Neglect (2013): Caregiver-fabricated illness in a child: a manifestation of child maltreatment. Pediatrics 132: 590597.

3. Jaghab K, Skodnek KB, Padder TA (2006): Munchausen's syndrome and other factitious disorders in children: case series and literature review. Psychiatry (Edgmont) 3: 46-55.

4. Bass C, Glaser D (2014): Early recognition and management of fabricated or induced illness in children. Lancet 19: 14121421.

5. Libow JA (2000): Child and adolescent illness falsification. Pediatrics 105: 336-342.

6. Meadow R (1977): Munchausen syndrome by proxy. The hinterland of child abuse. Lancet 2: 343-345.

7. Feldman MD, Brown RM (2002): Munchausen by proxy in an international context. Child Abuse Negl 26: 509-524.

8. Feldman KW, Feldman MD, Grady R, et al. (2007): Renal and urologic manifestations of pediatric condition falsification/Munchausen by proxy. Pediatr Nephrol 22: 849-856.

9. Trejo-Hernández J, Loredo-Abdalá A, Orozco-Garibay JM (2011): Munchausen syndrome by proxy in Mexican children: medical, social, psychological and legal aspects. Rev Invest Clin 63: 253-262.

10. Lieder HS, Irving SY, Mauricio R, Graf JM (2005): Munchausen syndrome by proxy: a case report. AACN Clin Issues 16: 178-184.

11. Huffman JC, Stern TA (2003): The diagnosis and treatment of Munchausen's syndrome. Gen Hosp Psychiatry 25: 358363.

12. Lasher LJ, Feldman MD (2004): Celiac disease as a manifestation of Munchausen by proxy. South Med J 97: 67-69.

13. American Psychiatric Association (1996): Diagnostic and Statistical Manual of Mental Disorders (DSM IV). American Psychiatric Association, Washington, DC; 483-487.

14. Horwath J (2003): Developing good practice in cases of fabricated and induced illness by carers: new guidance and the training implications. Child Abuse Rev 12: 58-63.

15. Sridharan S, Shukla D, Mehta R, Oswal R (2011): Munchausen syndrome masquerading as bleeding disorder in a group of pediatric patients. Indian J Psychol Med 33: 86-88.

16. Awadallah N, Vaughan A, Franco K, et al. (2005): Munchausen by proxy: a case, chart series, and literature review of older victims. Child Abuse Negl 29: 931-941.

17. Peebles R, Sabella C, Franco K, Goldfarb J (2005): Factitious disorder and malingering and malingering in adolescent girls: Case series and literature review. Clin Pediatr 44: 237-243.

18. Chiarini L, Presutti L (2012): Otolaryngology fantastica: the ear, nose, and throat manifestations of Munchausen's syndrome. Laryngoscope 122: 51-57.

19. Berent D, Florkowski A, Gałecki A (2010): Münchausen syndrome by proxy (przeniesiony zespół Münchausena). Psychiatr Pol 44: 245-254 [in Polish].

20. Persaud R (2005): Keeping Mum over child abuse. BMJ 330: 152.
21. Bass C, Jones D (2011): Psychopathology of perpetrators of fabricated or induced illness in children: case series. Br J Psychiatry 199: 113-118.

22. Tamay Z, Akcay A, Kilic G, et al. (2007): Corrosive poisoning mimicking cicatricial pemphigoid: Munchausen by proxy. Child Care Health Dev 33: 496-499.

23. Clin B, Ferrant O, Dupont C, Papin F (2009): Recurrent caustic esophagitis: a clinical form of Münchausen syndrome by proxy. Child Abuse Negl 33: 293-295.

24. Porter GE, Heitsch GM, Miller MD (1994): Munchausen syndrome by proxy: unusual manifestations and disturbing sequelae. Child Abuse Negl 18: 789-794.

25. Squires JE, Squires RH Jr (2010): Munchausen syndrome by proxy: ongoing clinical challenges. J Pediatr Gastroenterol Nutr 51: 248-253.

26. Rosenberg DA (1987): Web of deceit: a literature review of Munchausen syndrome by proxy. Child Abuse Negl 11: 547563.

27. Yates VM (1992): Factitious purpura. Clin Exp Dermatol 17: 238-239.

28. Kazak AE, Westervelt VD, Bracikowski A, Hassler C (1988): A systems-oriented treatment of an adolescent with factitious lip crusting. J Adolesc Health Care 9: 337-339.

29. Karnik AM, Farah S, Khadadah M, et al. (1990): A unique case of Munchausen' syndrome. Br J Clin Pract 44: 699-701.

30. Oldham L (1974). Facial pain as a presentation in Von Munchausen's syndrome: a case report. Br J Oral Surg 12: 86-90.

31. Zonuz AT, Treister N, Mehdipour F, et al. (2007): Factitial pemphigus-like lesions. Med Oral Patol Oral Cir Bucal 12: E205-208.

32. Cristóbal MC, Aguilar A, Urbina F, et al. (1987): Self-inflicted tongue ulcer: an unusual form of factitious disorder. J Am Acad Dermatol 17: 339-341.

33. Plassman R. (1994). The biography of the factitious-disorder patient. Psychother Psychosom 62: 123-128.

34. Özmen S, Özmen ÖA, Yılmaz T (2008): Clear otorrhea: a case of Munchausen syndrome in a pediatric patient. Eur Arch Otorhinolaryngol 265: 837-838.

35. Ben-Chetrit E, Melmed RN (1998): Recurrent hypoglycaemia in multiple myeloma: a case of Munchausen syndrome by proxy in an elderly patient. J Intern Med 244: 175-178.

36. Deimel GW, Burton MC, Raza SS, et al. (2012): Munchausen syndrome by proxy: an adult dyad. Psychosomatics 53: 294-299. 